\title{
EXPERIMENTOS ECONÔMICOS PARA ESTUDANTES DO ENSINO MÉDIO DA REDE PÚBLICA DE RIBEIRÃO PRETO/SP ${ }^{\dagger}$

\author{
ECONOMIC EXPERIMENTS FOR PUBLIC SCHOOL'S STUDENTS OF \\ RIBEIRÃO PRETO/SP
}

*Natália Nunes Ferreira Batista, **Roseli da Silva

\section{RESUMO}

Este artigo relata a experiência das docentes na condução de uma nova metodologia didática em economia voltada para o ensino de conceitos básicos a um público diversificado. O projeto foi aplicado em dez escolas públicas de Ensino Médio na cidade de Ribeirão Preto, com participação de quase 300 estudantes. Por meio de um jogo que simula o ambiente de mercado competitivo, alunos participantes do projeto puderam aprender conceitos básicos de economia (como os de oferta, demanda, formação de preço e equilíbrio de mercado). Assim, a experiência concreta dos alunos (produto de suas participações ativas no jogo) produz o material utilizado no processo de ensino-aprendizado de economia para o público leigo aplicado neste projeto de extensão universitária.

Palavras-chave: Experimentos econômicos. Ensino Médio. Ribeirão Preto.

\begin{abstract}
This article reports the experience of teachers in the conduct of a new didatics method in economics, focused on the teaching of basic concepts to a diverse audience. The project was implemented in ten public high schools in the city of Ribeirão Preto, with the participation of nearly 300 students. Through a game that simulates the environment of competitive market, students participating in the project were able to learn basic concepts of economics such as supply, demand, pricing and market balance. Thus, the actual experience of students - a product of their active participation in the game - produces the material used in the process of teaching and learning of economics applied to the lay public in this extension project.
\end{abstract}

Key words: Experimental economics. High school. Ribeirão Preto.

$\dagger \mathrm{O}$ projeto obteve apoio do Fundo de Fomento às Iniciativas de Cultura e Extensão da Pró-Reitoria de Cultura e Extensão Universitária da USP.

* Professora Doutora do Departamento de Economia da Faculdade de Economia e Administração de Ribeirão Preto (FEARP) da USP - e-mail: nbatista@fearp.usp.br. ** Professora Doutora do Departamento de Economia da Faculdade de Economia e Administração de Ribeirão Preto (FEARP) da USP. 


\section{INTRODUÇÃO}

O projeto "Experimentos Econômicos para Estudantes do Ensino Médio da Rede Pública de Ribeirão Preto" surgiu da convergência de ideais entre as duas coordenadoras em relação à importância das atividades de caráter extensionista como um dos pilares da Universidade de São Paulo, e legítimo meio de aproximação, diálogo e mútuo aprendizado entre a Universidade e a comunidade em que está inserida.

A iniciativa visou introduzir conceitos iniciais de economia por meio de uma metodologia inovadora a um público importante e normalmente sem acesso a tal conhecimento: os alunos do Ensino Médio de escolas públicas de Ribeirão Preto. Este artigo apresenta, de maneira resumida, a aplicação desta atividade de cultura e extensão realizada pelas autoras.

O conhecimento básico de economia, acreditamos, deve fazer parte da cultura geral de cidadãos bem informados, contribuindo para capacitá-los a tomar decisões mais apropriadas no seu dia a dia, seja em relação às suas compras diárias, seja em relação à alocação do seu tempo e de sua renda, ou mesmo em relação às escolhas de seus representantes políticos, que sempre apresentam plataformas sobre o que, quanto e como gastar do orçamento público.

Apesar de ser incipiente no Brasil, o ensino de economia em nível pré-universitário ${ }^{\dagger}$ é realidade em alguns países há algum tempo. Nos Estados Unidos, por exemplo, a discussão sobre a inserção do ensino de economia no nível médio começou na década de I970. Depois de uma série de decisões descentralizadas ocorridas ao longo da década de I980, em que cada estado optava por inserir ou não o ensino de economia em seus currículos de maneira direta, reservando uma disciplina específica para tal; atualmente aquele país conta com treze estados (26\%) em que economia é diretamente ensinada no nível médio. Mas, mesmo quando o ensino de economia não é realizado em uma disciplina específica, muitas vezes seus conceitos são abordados indiretamente no ensino tradicional de matemática, leitura e aulas de estudos sociais ${ }^{\ddagger}$.

$\dagger$ Existem algumas iniciativas esparsas, principalmente de entidades do setor privado ou do setor não governamental.

$\ddagger \quad$ Dados de I998 do Centro Nacional de Estatística Educacionais americano (NCES) mostravam que $46 \%$ do total de estudantes do Ensino Médio haviam feito algum curso chamado "economia".
Devido ao caráter descentralizado do ensino norte-americano, cada estado tem o direito de decidir se o ensino de economia entrará na grade curricular, e ainda se este aparecerá na forma obrigatória ou optativa. Então, paralelamente aos treze estados em que o ensino de economia está diretamente incluído na grade curricular, temos também nove estados em que um teste de alfabetização econômica é aplicado, e ainda quatro estados em que, apesar de não ter um curso de economia, o conteúdo deste está incluído no ensino, mesmo que não discriminadamente.

De uma maneira ou de outra, os jovens americanos têm a oportunidade de aprender conceitos econômicos através dos cursos de instituições americanas, história geral, educação cívica e do governo, estudos sociais, geografia, literatura e matemática.

Outro país que incentiva o ensino de economia de seus jovens é a Espanha. Neste caso, embora haja orientações gerais no currículo de Educación Secundaria Obligatoria, as regiões podem adaptar os conteúdos aos seus interesses e aspectos culturais regionais. Atualmente, em nível nacional, diversas universidades públicas organizam uma olimpíada de economia com o objetivo de estimular o estudo de economia e de temas empresariais entre os jovens, bem como o de fortalecer o vínculo com professores e alunos de economia do Ensino Médio, que poderão vir a se tornar futuros estudantes de economia.

No Brasil, a estabilização econômica alcançada a partir da implementação do Plano Real gerou um ambiente mais propício à discussão de outras importantes questões econômicas que, assim como a inflação, fazem parte do dia a dia dos cidadãos e influenciam sua tomada de decisão no âmbito pessoal e familiar. Neste novo cenário, surge a possibilidade de que o gasto de tempo e recursos da população que eram canalizados para a proteção contra a perda da renda real, causada pela inflação, passe a ser direcionado a questões de alocação desta renda, o que requer conhecimentos básicos de economia e finanças.

No entanto, para que a população se beneficie integralmente deste processo de maturidade econômica, é preciso que esteja relativamente preparada para lidar com os fatores relacionados às decisões de ordem econômica. Aprender a realizar escolhas, estando ciente tanto dos fatores envolvidos quanto das consequências embutidas em cada uma delas, pressupõe uma exposição ao campo de conhecimento específico e, a partir daí, torna-se um treino constante que 
envolve a capacidade de analisar os custos e benefícios associados a cada decisão.

A popularização de temas econômicos relevantes para o cotidiano de qualquer pessoa vem se exprimindo através da multiplicidade de canais por meio dos quais estes assuntos têm atingido o público leigo. Espalhamse no país cursos formulados por organizações não governamentais sobre educação econômica e de negócios voltados principalmente para o incentivo ao empreendorismo. Em algumas escolas, temas de economia são ensinados em sala de aula e (com frequência cada vez maior) programas de televisão abordam assuntos referentes à administração do orçamento doméstico.

Seguindo a constatação de que o domínio de conceitos básicos de economia é útil para a grande maioria das pessoas, este projeto teve como objetivo transmitir essas noções para alunos do Ensino Médio da Rede Pública de Ribeirão Preto. Acredita-se que uma instrumentação básica de economia fornecerá aos alunos uma visão clara dos fatores que interferem nas decisões de compra, do funcionamento dos mercados e, ainda, a importância da relação entre escolhas de bens e/ou estratégias distintas, auxiliando-os na condução da própria vida financeira.

A escolha do público-alvo deve-se à percepção de que temas econômicos e financeiros vêm se inserindo cada vez mais cedo na vida dos jovens e que, para os alunos da rede pública de ensino, a disponibilização de informações talvez não ocorra de maneira espontânea. Devido às características deste público, a transmissão das noções básicas foi realizada através da implementação de jogos em que a fixação do conceito ocorrerá através da participação do aluno em um experimento realizado em sala de aula. Nessa situação, os alunos atuam como agentes que tomam decisões em ambientes o mais próximo possível daquele encontrado na sua vida prática.

A maneira dinâmica com que os fenômenos econômicos são transmitidos através da aplicação dos jogos facilita a compreensão abrangente e profunda por parte do aluno, e diferencia esta iniciativa das demais que também direcionam-se ao público leigo. Este projeto tem também relação direta com a atividade acadêmica das docentes, pois propicia um aprendizado concreto do método de ensino que pode ser totalmente replicado em sala de aula, desde que os jogos sejam devidamente selecionados para os estudantes universitários.

Este artigo está composto de três partes, além desta introdução: na segunda seção, descrevemos a situação educacional de Ribeirão Preto, a partir da análise dos dados do Censo Demográfico do Censo Escolar, que nos permitiu mapear as condições educacionais e, assim, selecionar as escolas participantes de modo a refletir a diversidade socioeconômica e educacional encontrada na cidade. A terceira seção trata dos experimentos em sala a partir da perspectiva metodológica, descrevendo o experimento aplicado e os resultados obtidos. Concluímos com a avaliação das escolas participantes sobre o experimento e pontuando a relevância deste projeto também como experiência didática para as docentes, enriquecendo, assim, a metodologia de ensino aplicada dentro da universidade.

\section{MATERIAIS E MÉTODOS}

Dados do Censo Escolar de 2006 indicavam que a rede púbica que cobre o Ensino Médio no município de Ribeirão Preto somava 36 escolas, sendo que aproximadamente $92 \%$ delas eram da rede estadual. O tamanho do universo de estudo inviabilizava a visita a todas as escolas, pois a aplicação do experimento requer a presença efetiva das duas pesquisadoras. Por esse motivo o projeto contou com um período de análise pré-aplicação onde selecionamos doze escolas públicas participantes, cobrindo aproximadamente $33 \%$ do total de escolas públicas de Ribeirão Preto.

O processo de seleção destas escolas contou com análises da situação escolar do município (particularmente do nível médio de ensino), levantamento da situação socioeconômica de todos os subsetores da cidade, comparação da infraestrutura escolar e notas obtidas no ENEM de todas as escolas que possuíam Ensino Médio.

O panorama geral da situação escolar de Ribeirão Preto para o ano de 2006 apontava para uma piora em relação aos demais municípios paulistas. O subíndice do IPRS referente à escolaridade calculado pela Fundação $\mathrm{SEADE}^{\S}$ mostra que o município teve uma

\$ Este indicador, calculado pela Fundação Seade, mostra os níveis de desempenho dos municípios paulistas quanto à riqueza, longevidade e educação, as três dimensões que compõem o índice. Ele foi criado com o objetivo de colaborar na formulação, condução e acompanhamento de políticas públicas e planos de desenvolvimento das cidades do Estado de São Paulo. Devido a sua periodicidade bianual, o IPRS de 2008 traz informações referentes ao ano-base de 2006. Infelizmente, até a finalização do projeto, dados do IPRS 2010 ainda não estavam disponíveis. 
melhora entre 2000 e 2006 , mas ela não chegou a ser suficiente para manter sua posição no ranking municipal. Ao contrário, a Tabela I (ver Anexo) mostra que no quesito educacional a cidade de Ribeirão Preto caiu várias posições.

Como a dimensão educacional que compõe o índice IPRS ${ }^{\pi}$ concentra-se na situação dos jovens de faixa etária entre I5 a I7 anos - justamente aqueles que deveriam estar cursando o Ensino Médio - é provável o baixo desempenho relativo em Ribeirão Preto esteja refletindo as dificuldades básicas de se manter os jovens na escola por reprovação, abandono e atraso escolar. Como a última informação disponível diz respeito a 2006, é possível que a realidade educacional da cidade tenha se alterado entre aquele ano e o momento de efetuação do projeto. No entanto, temos consciência que o quadro não pode ter sofrido uma mudança muito acentuada, pois toda alteração de política educacional só apresenta resultados no médio/longo prazo.

\section{ESCOLAS PARTICIPANTES:}

\section{SELEÇÃO E SITUAÇÃO SOCIOECONÔMICA}

A realidade das escolas públicas de Ribeirão Preto é bastante diversa, tanto em termos do público que atende quanto aos recursos físicos e humanos que comportam. Por esse motivo, para que o projeto "Experimentos Econômicos para estudantes do Ensino Médio da Rede Pública de Ribeirão Preto" fosse implementado, inicialmente foi preciso selecionar as escolas que seriam visitadas, com vistas a refletir tal diversidade.

Dentre as 33 escolas públicas, precisávamos escolher unidades de todas as regiões da cidade: norte, sul, leste, oeste e centro. Esta seleção foi realizada por uma série de indicadores, tanto escolares (Censo Escolar e desempenho da escola no ENEM) quanto socioeconômicos (Censo Demográfico).

O âmbito socioeconômico municipal só é efetivamente captado pelo Censo Demográfico. Por isso foi preciso criar índices para os diversos subsetores da cidade com o intuito de contextualizar a realida-

II O IPRS educacional é mensurado através dos seguintes indicadores: taxa de atendimento à pré-escola entre as crianças de 5 a 6 anos, proporção de pessoas de I 5 a I 7 anos que concluíram o Ensino Fundamental, proporção de pessoas de I5 a I7 anos com pelo menos quatro anos de estudo, proporção de pessoas de I8 a I9 anos com Ensino Médio completo. de socioeconômica em que as escolas estão inseridas ${ }^{* *}$. Assim, foi possível ter, além dos indicadores escolares, também indicadores socioeconômicos para cada área $^{\dagger \dagger}$. No entanto, devido à grande defasagem dos dados computados pelo último Censo Demográfico, estamos cientes da possibilidade de que cada região da cidade tenha sofrido mudanças acentuadas. Já os dados referentes à situação escolar foram coletados no Censo Escolar de 2006, que computa informações básicas para todas as escolas que possuem Ensino Médio e, através de seus endereços, verificamos em qual setor censitário cada uma delas se enquadrava.

Depois de analisar os dados socioeconômicos ${ }^{\S \S}$ e escolares de cada subsetor da cidade, chegamos à seguinte amostra final:

- Região Norte: três escolas selecionadas (Prof. Walter Paiva, Prof. João Augusto de Melo, Vereador Orlando)

- Região Sul: duas escolas selecionadas (Prof. Alcides Correa, Expedicionários Brasileiros)

- Região Leste: duas escolas selecionadas (Miguel Jorge e Prof. Alpheu Dominiguetti)

- Região Oeste: três escolas (Profa. Amélia dos Santos, Profa. Djanira Velho e Dr. João Palma)

- Região Central: duas escolas (Cônego Barros e Otoniel Mota)

Apesar de selecionarmos doze escolas, duas delas não aderiram ao projeto (Expedicionários Brasilei-

** Para realizar esse trabalho foi necessário estabelecer uma correspondência entre o código do setor censitário presente no Censo Demográfico e os bairros da cidade.

$\dagger \dagger$ As variáveis do Censo Demográfico utilizadas foram: proporção de jovens de I5-I7 anos no setor censitário, proporção de pretos e pardos (homens e mulheres) por setor censitário, proporção de crianças entre 6 e I7 anos que não frequentam a escola por setor censitário, proporção de jovens entre I8 e 2I anos que não frequentam a escola por setor censitário, proporção de pessoas acima de IO anos que possuem trabalho remunerado por setor censitário, salário médio de homens e mulheres (separadamente) por setor censitário.

If As variáveis de infraestrutura escolar que utilizamos foram: existência de biblioteca na escola e laboratórios (ciências/ informática), se a escola utiliza computador em sala de aula, se a escola participa do Programa TV Escola. O Programa TV Escola é um canal de televisão do Ministério da Educação que capacita, aperfeiçoa e atualiza educadores da rede pública desde I996. Sua programação exibe, nas 24 horas diárias, séries e documentários estrangeiros e produções próprias.

§§ Uma tabela resumo com a situação socioeconômica de Ribeirão Preto encontra-se no anexo. 
ros na zona sul e o Prof. Alpheu Dominiguetti na zona leste), o que diminuiu nossa amostra para dez escolas. Esta contingência fez com que as regiões sul e leste ficassem sub-representadas. Nas dez escolas visitadas o projeto contou com a participação no total de 297 alunos.

Para a caracterização física das escolas, utilizamos os dados do Censo Escolar, já as informações socioeconômicas dos alunos participantes foram obtidas através da aplicação de um questionário realizada antes do início do jogo. A Tabela I (ver Anexo) mostra as informações da infraestrutura escolar e a quantidade de alunos que participou do projeto em cada escola selecionada.

Chama a atenção que nem todas as escolas visitadas tinham biblioteca. A Tabela I (ver Anexo) mostra que enquanto três escolas não tinham laboratório de ciências e uma não apresentava laboratório de informática, quatro delas não tinham biblioteca. Já o Programa TV Escola contava com a adesão de sete escolas e, dentre as três que não utilizavam este instrumento, duas também não tinham biblioteca. Excluindo estas duas variáveis (biblioteca e Programa TV Escola), nota-se que, quanto à infraestrutura, as escolas são praticamente similares ${ }^{\text {IIT }}$. Desta maneira, as informações sobre a existência de biblioteca e adesão ao Programa TV Escola foram cruciais para nossa seleção amostral.

Além das variáveis do Censo Escolar apontadas acima, verificamos também o desempenho das escolas no exame do ENEM, em 2007. A Tabela 2 (ver Anexo) mostra a adesão e o desempenho na prova do ENEM das escolas visitadas, comparando-as com o desempenho médio de Ribeirão Preto.

Como aconteceu com a variável biblioteca, no caso do desempenho no exame do ENEM, também selecionamos tanto escolas que tiveram boas notas em relação ao município, quanto aquelas que tiveram desempenho aquém. No que tange à participação dos alunos neste exame, nossa amostra conta com escolas em que a proporção de alunos que fizeram a prova está abaixo de $10 \%$ e ainda aquelas onde mais da metade dos alunos habilitados fizeram a prova em 2007.

No entanto, os dados da Tabela 2 (ver Anexo) apontam que não é possível estabelecer nenhuma relação entre a adesão dos alunos e o desempenho na pro-

II As demais variáveis selecionadas (como quadra esportiva, pátio, sala de professor) não mostram diferenças significativas entre as escolas e por este motivo não foram apresentadas. va, pois encontramos tanto escolas com elevada participação e nota baixa, quanto escolas onde menos de $30 \%$ dos alunos participaram e obtiveram notas altas.

A condução do projeto contou também com a aplicação de um questionário socioeconômico aos alunos participantes. Além das variáveis importantes como grau de instrução da mãe/pai e renda familiar, coletamos também informações que nos indicassem o tipo de arranjo familiar, número de livros lidos por ano, atraso escolar, pretensão de cursar nível superior, forma de obtenção de informação (TV, jornal, internet etc). A Tabela 3 (ver Anexo) mostra o resultado de uma das variáveis mais relevantes quanto ao nível educacional familiar da qual os alunos participantes do projeto estão expostos: o nível educacional das mães.

Os dados acima mostram que apenas nas escolas da região norte encontramos alunos em que as mães não completaram o Ensino Fundamental. A escolaridade da maioria das mães dos alunos que participaram do experimento situa-se entre Ensino Fundamental completo e Ensino Médio completo. Em algumas escolas localizadas no centro, oeste e leste, os participantes têm mãe com nível universitário.

Apesar do desempenho na prova do ENEM fornecer informações sobre outra amostra de alunos, nota-se alguma relação entre este resultado por escola e o nível educacional das mães dos atuais alunos. Assim, se supusermos que o perfil dos alunos destas escolas não mudou muito, nota-se que a herança educacional da família contribui consideravelmente para os desempenhos dos alunos. A Tabela 3 (ver Anexo) mostra que das seis escolas em que as mães dos alunos possuem nível universitário, quatro apresentaram um desempenho no ENEM acima da média da cidade.

Quanto às perspectivas futuras de estudo, a Tabela 4 (ver Anexo) mostra a porcentagem de alunos e alunas de cada turma que demonstraram interesse em cursar o nível superior após o término do Ensino Médio.

Em mais da metade das escolas visitadas, a proporção de alunas que deseja continuar os estudos é superior a dos alunos. Em duas delas todos eles expressaram vontade de cursar a faculdade, e em outras duas, os garotos mostraram interesse maior que as garotas. Não se observa nenhuma relação entre o desempenho no exame do ENEM em 2007 e este interesse em dar continuidade aos estudos. Isto aponta que os alunos de maneira geral se sentem incentivados, ou que percebem a importância do nível de instrução 
para um melhor posicionamento no mercado de trabalho. Este desejo de cursar a universidade é elevado em todas as turmas, independente do nível de atraso escolar.

\section{EXPERIMENTOS EM SALA DE AULA}

A metodologia experimental em Economia ganhou maior evidência a partir da atribuição do prêmio Nobel de 2002 ao economista Vernon Smith e ao psicólogo Daniel Kahneman, por suas contribuições em economia experimental, testando modelos econômicos tradicionais em laboratórios e, em psicologia cognitiva, estudando o processo decisório e o julgamento humanos, respectivamente. No entanto, já no início da década de I940, Edward Chamberlin [2] retratou experimentos realizados com seus alunos na Universidade de Harvard, nos quais simulou trocas em um mercado competitivo.

A aplicação de experimentos na área de Economia vem se intensificando nas últimas décadas, e ampliou sua aceitação como um modo produtivo de conduzir pesquisa na área de ciências sociais, buscando comprovações empíricas em experiências laboratorias e/ou de campo de alguns aspectos teoricamente estabelecidos $^{* * *}$. A metodologia empregada na economia experimental divide-se em métodos de laboratório, em que o experimento é mantido sob controle do pesquisador e em pesquisa de campo. No último caso, a estruturação da aplicação deve ser bastante meticulosa para que os efeitos decorrentes de distorção no ambiente, na instituição ou no comportamento do público-alvo, sejam minimizados.

O trabalho de Holt e Tanga [4] discutem o uso de experimentos em sala de aula como exercícios curtos e interativos, concebidos para facilitar a compreensão das ideias-chave da economia. Por meio desses experimentos, os alunos produzem os dados que podem lhes permitir a descoberta por eles próprios dos princípios relevantes de economia, que são, em sequência, cuidadosamente estruturados numa discussão entre professor e alunos. Os autores acreditam que experimentos eficientes são capazes de induzir a aprendizagem em um nível mais profundo, em que se pode, a partir dos resultados, apontar a utilidade da abstração apresentada na teoria econômica.

*** Dentre eles destacam-se as escolhas dos agentes diante de problemas que envolvem o comportamento estratégico (provisão de bens públicos, coordenação/equilíbrio, regulação de mercados etc.).
No artigo citado anteriormente, os autores descrevem como projetar e pôr em prática experiências pedagógicas com apoios simples, sem a necessidade de computadores ou laboratórios próprios para execução de experimentos controlados. Os dois tipos mais populares de experimentos em sala de aula são de mercados competitivos e de teoria dos jogos. Nas escolas visitadas, foi realizado o primeiro tipo.

Selecionamos o experimento que introduz conceitos referentes ao mercado competitivo devido a sua capacidade de abordar importantes conceitos econômicos (oferta e demanda), e por estar identificado com a prática do dia a dia de todos (dos alunos, dos seus familiares, dos professores, dos cidadãos em geral) que, inevitavelmente, compram ou vendem alguma mercadoria, bem ou serviço.

A execução de tal tarefa seguiu Holt [3], autor que utiliza a estrutura de um jogo em que os estudantes são colocados em uma situação que simula o funcionamento de mercados competitivos. Para tanto, separamos a classe entre compradores e vendedores e usamos um baralho para distribuir de maneira aleatória valores de custo de produção aos vendedores (cartas de cor preta), e valores que apontam a quantia máxima que cada comprador está disposto a pagar pela mercadoria (cor vermelha). O exercício dura entre 40 minutos e I hora para leitura de instruções e jogo, mais vários turnos de 5 minutos para os períodos das negociações. Vendedores não podem vender abaixo do custo e compradores não podem pagar mais que o valor inscrito em suas respectivas cartas.

Após o término das negociações, inicia-se o período de discussões. Um ponto importante na discussão é permitir que os alunos consigam descobrir que o preço deve ser um equilíbrio das quantidades ofertadas e demandadas.

\section{RESULTADOS E DISCUSSÃO}

Como resultado direto da aplicação deste projeto, os quase 300 estudantes de Ensino Médio de Escolas Públicas de Ribeirão Preto adquiriram capacidades cognitivas referentes a temas econômicos, particularmente o funcionamento do mercado e domínio dos fatores relevantes ao processo de alocação de recursos, envolvidos tanto nas decisões de consumo quanto nas de produção.

O experimento foi aplicado segundo instruções 
encontradas em Holt [3] e descritas na subseção anterior, respeitando sempre o total de oito rodadas de negociação e mantendo o preço de equilíbrio teórico em seis unidades monetárias (isto é possível mediante a escolha dos números de cartas de compradores e vendedores).

Como exemplo, reportamos a seguir os resultados para uma das escolas, a E. E. Otoniel Mota, localizada na região central da cidade. Esse resultado é muito semelhante aos obtidos para as demais escolas participantes $^{\dagger \dagger \dagger}$. Nesta escola, tínhamos I6 compradores com cartas vermelhas com a seguinte distribuição \{о, Iо, Іо, 9, 9, 9, 8, 8, 8, 7, 7, 6, 6, 5, 5, 4\}, е I6 vendedores, cujas cartas pretas estavam distribuídas como $\{2,2,2,3,3,3,4,4,4,5,5,6,6,7,7,8\}$, informações não conhecidas pelos jogadores no início de jogo, obviamente. Como havia 38 alunos, 6 deles participaram como registradores de preços.

As instruções foram lidas e as cartas distribuídas para que a primeira rodada fosse realizada, na qual I4 negócios foram fechados. O Gráfico I mostra os preços fechados a cada rodada, e é facilmente observado que na primeira rodada os preços negociados têm uma amplitude elevada, do mínimo de 3 ao máximo de 8 . Ao longo das rodadas, enquanto cada aluno buscava seu autointeresse (maximizar seus ganhos), buscando fechar o melhor negócio no mercado, naturalmente os preços negociados começam a convergir para um valor em torno do equilíbrio teórico, o valor 6 - na última rodada, dos 12 negócios fechados, 9 marcaram em seis. Ao longo das negociações, os participantes vão sendo informados dos preços que estão sendo fechados, o que mimetiza o papel da informação perfeita nos mercados concorrenciais.

Enquanto as rodadas estão ocorrendo, cada participante, de posse dessa informação e sabendo o número que está em sua carta - para o comprador, o número representa a sua disposição máxima a pagar pelo bem; para o vendedor, o custo para produzir, e, portanto, o preço mínimo que poderia vender -, vai ao mercado em busca de obter o maior ganho, que será premiado ao final do experimento (no caso, os prêmios eram caixas de bombons, uma para o comprador e outra para o vendedor de maiores ganhos).

$\dagger \uparrow \dagger$ Devido à limitação de espaço, não será possível apresentar o resultado de todas as escolas. Para demais informações, entrar em contato com as autoras.
Depois que as oito divertidas rodadas acontecem, a primeira informação que sistematizamos e começamos a discutir são os preços negociados, fazendo na lousa o gráfico de dispersão de preços ao longo das rodadas (Gráfico I).

\section{GRÁFICO 1}

Experimento realizado na E. E. Otoniel Mota Dispersão de preços

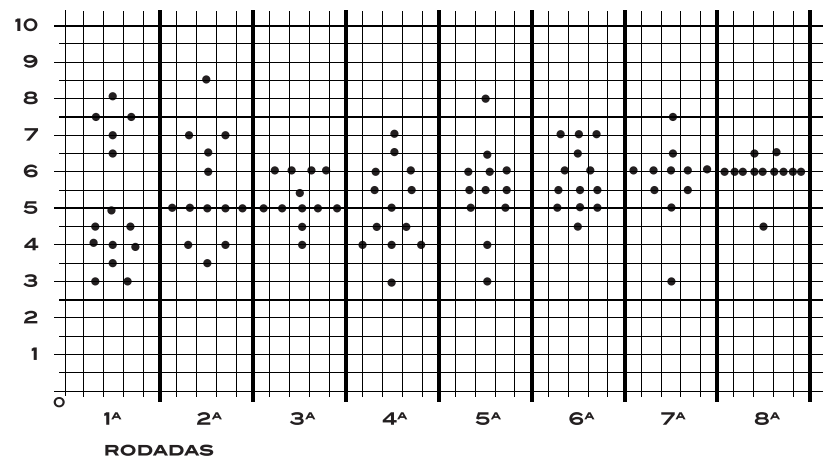

Nesse momento, a discussão é encaminhada no sentido de que os alunos compreendam que aquela simulação que fizemos - que se aproxima muito do que acontece na realidade em muitos mercados, tais como as bolsas de valores, as feiras livres, alguns mercados agrícolas, ou mesmo o varejo de bens de consumo básico - gerou naturalmente resultados de preços negociados que convergem para um determinado preço, que aprendem neste momento ser denominado "preço de equilíbrio", em mercados competitivos.

Inicia-se, então, uma discussão sobre o papel de não se especificar o bem que se está negociado, explicando aos alunos o papel das preferências nas decisões de compra que, em conjunto com a renda e os preços, tanto do bem que se está comprando quanto dos bens relacionados, determina o valor que estava estampado na carta vermelha (comprador) aleatoriamente recebida no jogo, agora denominada de "disposição a pagar".

Em seguida, discutem-se os fatores que poderiam explicar e determinar os custos de produção, também recebidos aleatoriamente pelos vendedores, estampados nas cartas pretas, que, a partir da participação e sugestões dos próprios alunos, vão sendo agrupados em custos de insumos (capital e trabalho) e de matérias-primas; destaca-se também o papel da tecnologia de produção (o modo de fazer o produto) na constituição daquele custo. 
A partir daí, os gráficos de demanda e oferta são traçados na lousa, permitindo a discussão de porque alguns compradores não faziam negócios, pois tinham baixa disposição a pagar, assim como alguns vendedores, com elevados custos. A partir do conjunto de cartas de compradores e vendedores, agora revelado aos alunos, e enfatizando que os compradores (vendedores) conseguiam maiores ganhos, quanto maior (menores) a disposição a pagar (os custos), traçamos as curvas de oferta e demanda, tal qual o Gráfico 2:

\section{GRÁFICO 2}

Experimento realizado na E.E. Otoniel Mota Demanda e Oferta

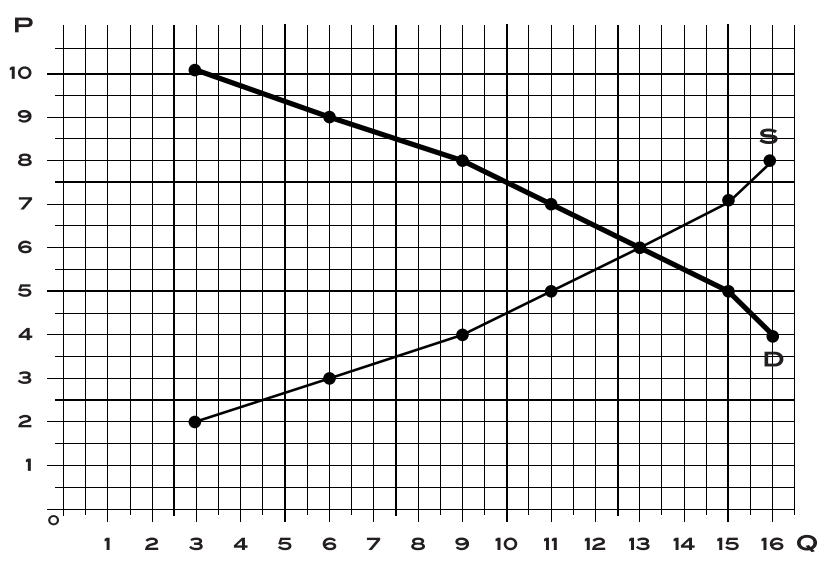

Em geral, devido ao pouco tempo disponível para análise dos resultados, os principais conceitos discutidos com os alunos foram: os fatores que influenciam a disposição a pagar; fatores que determinam os custos econômicos de produção; o significado do equilíbrio de mercado e como a busca do autointeresse leva a tal equilíbrio; o papel das regras do jogo na consecução de tais resultados e discussões marginais sobre o efeito de combinações para praticar determinados preços no mercado, do lado dos compradores ou de vendedores, caracterizando estratégias não concorrenciais, muito comuns nos mercados reais.

Assim, a partir da experiência concreta e dos resultados dela obtidos, os conceitos de mercados competitivos, demanda e oferta, e equilíbrio de mercado, bem como de excedentes do consumidor e vendedor (ganhos) são introduzidos e facilmente apreendidos pelos alunos. Toda uma discussão sobre o efeito de controles de preços, de tributação e de estruturas de mercados pode decorrer dessa experiência quando utilizada num contexto de uma sequência de aulas.

\section{CONCLUSÕES}

A execução do projeto "Experimentos Econômicos para Estudantes do Ensino Médio da Rede Pública de Ribeirão Preto" mostrou-se importante em dois aspectos distintos: primeiramente, o fornecimento de conceitos econômicos básicos e fundamentais para a percepção do funcionamento dos mercados, a estudantes de ensino médio e, em segundo lugar, mas não menos relevante, a experiência didática para as autoras.

No primeiro caso, apesar de não mensurarmos a aquisição de capacidades cognitivas econômicas dos alunos, auferimos de forma indireta a validade do projeto do ponto de vista dos beneficiários através da aplicação de um questionário junto aos diretores ou coordenadores das escolas ${ }^{\ddagger \ddagger \ddagger}$. Não se pretende, por meio de tal instrumento simples, demonstrar a efetividade da metodologia, tampouco avaliar o grau de conhecimento em economia adquirido pelos alunos participantes do projeto.

Observamos, ainda, que o desenvolvimento de tais capacidades é efetivamente construído em um prazo mais longo e, principalmente, mediante um trabalho conjunto com a escola. A crescente inserção do ensino de finanças nas escolas é apenas uma das faces do ensino de economia. Acreditamos que podemos ensinar nossos jovens a pensar a economia de uma maneira muito mais abrangente, em que eles assumam uma posição que vai além de consumidor ou de investidor, encaminhando-os a uma reflexão sobre suas escolhas enquanto cidadãos ${ }^{\$ \S \S}$.

$\mathrm{Na}$ avaliação subjetiva sobre a efetividade do projeto como uma atividade de extensão, observamos que, das dez escolas visitadas, apenas duas delas nunca tinham participado de projetos realizados por docentes/pesquisadores da Universidade de São Paulo. As demais afirmaram ter participado de projetos, sobretudo na área de Saúde.

I† Esta aplicação foi realizada meses após a visita. Diretores ou coordenadores responderam, via contato telefônico, a várias questões de caráter qualitativo.

§§ A metodologia de experimentos em sala de aula é capaz de englobar vários tópicos de economia, como escolha pública (escolha eleitoral, provisão de bens públicos etc.), fluxo circular da renda (circulação de bens, serviços, recursos produtivos e moeda), política monetária (oferta de moeda, inflação, juros etc.). 
Numa escala de I a 5 , sendo 5 o máximo, os representantes das escolas participantes avaliaram que a participação da escola no Projeto de Extensão em questão contribuiu para aproximar a Universidade de São Paulo à realidade dos estudantes de Ensino Médio de Escolas Públicas, com média 4,40, e que tanto os professores quanto os alunos foram bastante receptivos ao projeto (médias 4,4 e 4,3, respectivamente). Metade dos respondentes informou que os alunos participantes se manifestaram, para a direção/coordenação ou para professores, em relação aos resultados e que gostaram da experiência (média 4,4 ), e houve interesse em saber mais sobre as possibilidades de estudo na Universidade de São Paulo. Questionados se gostariam que a escola sob sua direção/coordenação participasse novamente de um projeto com mesmo propósito e metodologia do projeto "Experimentos Econômicos para Estudantes do Ensino Médio da Rede Pública de Ribeirão Preto", a resposta foi bastante positiva, apresentando média de 4,7 .

Quanto ao segundo aspecto, da relevância didática do projeto, sua condução requisitou das autoras uma pesquisa bastante abrangente sobre novos métodos de ensino de economia. A literatura sobre o uso de experimentos no ensino de economia de Becker e outros autores [1] aponta que a eficácia dos jogos como método pedagógico requer que, além da sua simples aplicação, o professor utilize os dados gerados para uma profunda discussão com os alunos. No decorrer do curso, o professor pode recorrer à experiência do jogo para continuar aprofundando outros conceitos. No entanto, a condução desta "profunda discussão" não se faz de maneira simples e direta.

Ao longo do projeto, foi necessária a aquisição de capacidades didáticas diferenciadas para lidar com um público diferente a cada aplicação do jogo. Observamos, na prática, que também nós, professores, devemos nos conter e ter atenção suficiente com a linguagem utilizada para não influenciar os alunos, levantando questões capazes de induzir o raciocínio deles, que será o meio efetivo da aprendizagem ativa. Como, neste projeto, tínhamos um único encontro com cada turma, foi preciso conduzir a discussão de maneira concisa, procurando captar a atenção dos alunos com exemplos relevantes para a apreensão dos conceitos principais e do resultado básico: a ação autointeressada de compradores e vendedores em mercados competitivos produz um preço de equilíbrio.
Por todos esses fatores, o projeto mostrou-se muito rico para o próprio aprendizado das autoras e, certamente, nossos alunos na Universidade de São Paulo foram e continuarão sendo indiretamente beneficiados por esta experiência.

\section{AGRADECIMENTOS}

As autoras agradecem às escolas que aceitaram participar do projeto e aos professores que cederam suas aulas para a aplicação do jogo.

\section{REFERÊNCIAS BIBLIOGRÁFICAS}

[1] BECKER, W. E.; WATTS, M.; BECKER, S. R. Teaching Economics: more alternatives to chalk and talk. Cheltenham-UK: Edward Elgar Publishing Limited, 2006, p. 225.

[2] GHAmberLiN, E. H. An Experimental Imperfect Market. Journal of Political Economy. 1948, LVI, n. 2 (abril), p. 95-108.

[3] HOLT, G. A. Classroom Games: Trading in a Pit Market. Journal of Economic Perspectives. I996, v. IO, n. I, p. 193-203.

[4] HOLT, G. A.; TANGA, M. Experimental Economics in the Glassroom. In: WALSTAD, W. B.; SAUNDERS, P., ed. Teaching undergraduate economics. Boston: Irwin/McGraw-Hill, I998, p. 257-268. 


\section{ANEXO}

\section{TABELA 1}

Índice de Responsabilidade Social - Ribeirão Preto

\begin{tabular}{|c|c|c|c|c|c|c|}
\hline \multirow{2}{*}{$\begin{array}{l}\text { ANO } \\
\text { BASE }\end{array}$} & \multicolumn{3}{|c|}{ SUBÍNDICE IPRS } & \multicolumn{3}{|c|}{ RANKING MUNICIPAL } \\
\hline & RIQUEZA & LONGEVIDADE & ESCOLARIDADE & RIQUEZA & LONGEVIDADE & ESCOLARIDADE \\
\hline 2000 & $6 \mathrm{I}$ & 70 & 50 & $39^{\circ}$ & $\mathrm{I} 8 \mathrm{I}^{\circ}$ & $134^{\circ}$ \\
\hline 2002 & 49 & 75 & 57 & $43^{\circ}$ & $99^{\circ}$ & $210^{\circ}$ \\
\hline 2004 & 52 & 76 & 57 & $39^{\circ}$ & $94^{\circ}$ & $260^{\circ}$ \\
\hline 2006 & 54 & 75 & 68 & $46^{\circ}$ & $169^{\circ}$ & $268^{\circ}$ \\
\hline
\end{tabular}

Fonte: SEADE, Índice de Responsabilidade Social (vários anos)

\section{TABELA 2}

Informações escolares e quantidade de alunos que participaram do projeto

\begin{tabular}{|c|c|c|c|c|c|c|c|}
\hline \multirow{2}{*}{$\begin{array}{l}\text { SUB- } \\
\text { SETOR }\end{array}$} & \multirow{2}{*}{ ESCOLA } & \multirow{2}{*}{ ALUNOS } & \multirow{2}{*}{ BIBLIOTECA } & \multicolumn{2}{|c|}{ LABORATÓRIOS } & \multirow{2}{*}{$\begin{array}{l}\text { COMPUTA- } \\
\text { DOR AULA }\end{array}$} & \multirow{2}{*}{$\begin{array}{l}\text { PROGRAMA TV } \\
\text { ESCOLA TV }\end{array}$} \\
\hline & & & & INFORMÁTICA & CIÊNCIAS & & \\
\hline $\mathrm{N}-2$ & $\begin{array}{l}\text { I. Prof. Walter } \\
\text { Paiva }\end{array}$ & 28 & I & I & I & não & $\operatorname{sim}$ \\
\hline $\mathrm{N}-5$ & $\begin{array}{l}\text { 2. Prof. João } \\
\text { Augusto de Melo }\end{array}$ & 27 & O & I & I & não & não \\
\hline $\mathrm{N}-\mathrm{IO}$ & $\begin{array}{l}\text { 3. Vereador } \\
\text { Orlando Vitaliano }\end{array}$ & 33 & 0 & I & I & não & $\operatorname{sim}$ \\
\hline S-I & $\begin{array}{l}\text { 4. Prof. Alcides } \\
\text { Correa }\end{array}$ & 30 & O & I & o & não & $\mathrm{n}$ \\
\hline $\mathrm{L}-7$ & 5. Miguel Jorge & 20 & I & I & O & não & não \\
\hline O-6 & $\begin{array}{l}\text { 6. Profa. Amélia } \\
\text { dos Santos Musa }\end{array}$ & I9 & O & I & I & não & $\operatorname{sim}$ \\
\hline O-6 & $\begin{array}{l}\text { 7. Profa. Djanira } \\
\text { Velho }\end{array}$ & 40 & I & I & I & não & $\operatorname{sim}$ \\
\hline $\mathrm{O}-\mathrm{I} 2$ & $\begin{array}{l}\text { 8. Dr. João Palma } \\
\text { Guião }\end{array}$ & 29 & I & O & ० & não & $\operatorname{sim}$ \\
\hline $\mathrm{CE}$ & 9. Cônego Barros & 33 & I & I & I & não & $\operatorname{sim}$ \\
\hline CE & IO. Otoniel Mota & 38 & I & I & I & não & $\operatorname{sim}$ \\
\hline
\end{tabular}

Fonte: Censo Escolar, 2006 
TABELA 3

Participação e Notas - Prova ENEM 2007

\begin{tabular}{|c|c|c|c|c|}
\hline LOCALIZAÇÃO & ESCOLA & PROPORÇÃO DE PARTICIPANTES & $\begin{array}{l}\text { NOTA PROVA } \\
\text { OBJETIVA E REDAÇÃO }\end{array}$ & $\begin{array}{c}\text { DIFERENÇA: ESCOLA - RIBEIRÃO } \\
\text { OBJETIVA E REDAÇÃO }\end{array}$ \\
\hline $\mathrm{N}-2$ & I & $8,4 \%$ & 46,0 & $-3,4$ \\
\hline $\mathrm{N}-5$ & 2 & $\mathrm{I} 5,4 \%$ & 48,2 & $-\mathrm{I}, 2$ \\
\hline $\mathrm{N}-\mathrm{IO}$ & 3 & I9, O\% & 48,0 & $-\mathrm{I}, 4$ \\
\hline S-I & 4 & $60,2 \%$ & 46,4 & $-3,0$ \\
\hline $\mathrm{L}-7$ & 5 & $22,2 \%$ & 49,7 & 0,3 \\
\hline O-6 & 6 & $26,5 \%$ & 50,7 & $\mathrm{I}, 3$ \\
\hline O-6 & 7 & $27,5 \%$ & $5 \mathrm{I}, 4$ & 2,0 \\
\hline $\mathrm{O}-\mathrm{I} 2$ & 8 & $\mathrm{I} 3, \mathrm{I} \%$ & 46,5 & $-2,9$ \\
\hline $\mathrm{CE}$ & 9 & $56,7 \%$ & 52,9 & 3,5 \\
\hline $\mathrm{GE}$ & IO & $5 \mathrm{I}, 7 \%$ & $55, \mathrm{I}$ & 5,7 \\
\hline \multicolumn{2}{|c|}{ Ribeirão Preto } & & 49,4 & \\
\hline
\end{tabular}

Fonte: ENEM, 2007

TABELA 4

Distribuição dos alunos segundo o nível educacional da mãe (\%)

\begin{tabular}{|c|c|c|c|c|c|c|c|c|}
\hline \multirow{2}{*}{$\begin{array}{l}\text { SUB- } \\
\text { SETOR }\end{array}$} & \multirow{2}{*}{ ESCOLA } & \multirow{2}{*}{ SEME.F. } & \multicolumn{2}{|c|}{ ENSINO FUNDAMENTAL } & \multicolumn{2}{|c|}{ ENSINO MÉDIO } & \multicolumn{2}{|c|}{ SUPERIOR } \\
\hline & & & INCOMPLETO & COMPLETO & INCOMPLETO & COMPLETO & INCOMPLETO & COMPLETO \\
\hline $\mathrm{N}-2$ & I & $\mathrm{I} 4,3$ & 50,0 & $7, \mathrm{I}$ & 3,6 & 25,0 & 0,0 & ০,० \\
\hline $\mathrm{N}-5$ & 2 & 12,0 & 48,0 & 8,0 & I6, o & 12,0 & ०,० & 4,0 \\
\hline N-IO & 3 & I 5,2 & 48,5 & $\mathrm{I} 5,2$ & $6, \mathrm{I}$ & $\mathrm{I} 5,2$ & 0,0 & 0,0 \\
\hline S-I & 4 & 0,0 & 36,7 & 20,0 & 6,7 & 36,7 & 0,0 & 0,0 \\
\hline $\mathrm{L}-7$ & 5 & 0,0 & 30,0 & I5, O & 20,0 & IO,O & IO,O & I5, O \\
\hline O-6 & 6 & 0,0 & 36,8 & IO, 5 & $2 \mathrm{I}, \mathrm{I}$ & 26,3 & 5,3 & 0,0 \\
\hline O-6 & 7 & 0,0 & 30,0 & $\mathrm{I} 2,5$ & 5,0 & 37,5 & 5,0 & IO,O \\
\hline $\mathrm{O}-\mathrm{I} 2$ & 8 & 0,0 & 20,7 & I7, 2 & $\mathrm{I} 7,2$ & 34,5 & 0,0 & IO, 3 \\
\hline $\mathrm{CE}$ & 9 & 0,0 & $2 \mathrm{I}, 2$ & $\mathrm{I} 5,2$ & $9, \mathrm{I}$ & 39,4 & $6, \mathrm{I}$ & 9,I \\
\hline $\mathrm{CE}$ & IO & 0,0 & 2,6 & 7,9 & $\mathrm{I} 3,2$ & 47,4 & 7,9 & $2 \mathrm{I}, \mathrm{I}$ \\
\hline Total & & $4, \mathrm{I}$ & $3 I, 2$ & I2, 9 & Io, 8 & 30,2 & 3,4 & 7,5 \\
\hline
\end{tabular}

Fonte: Elaboração própria. 


\section{TABELA 5}

Proporção dos alunos que pretendem fazer faculdade (\%)

\begin{tabular}{|c|c|c|c|c|c|c|c|c|c|c|c|}
\hline SUBSETOR & $\mathrm{N}-2$ & $\mathrm{~N}-5$ & $\mathrm{~N}-\mathrm{IO}$ & S-I & $\mathrm{L}-7$ & O-6 & O-6 & $\mathrm{O}-\mathrm{I} 2$ & $\mathrm{CE}$ & $\mathrm{CE}$ & Total \\
\hline ESCOLA & I & 2 & 3 & 4 & 5 & 6 & 7 & 8 & 9 & IO & - \\
\hline GAROTAS & 85,7 & $7 \mathrm{I}, 4$ & 88,9 & 87,5 & 92,9 & IOO,O & 90,0 & IOO, O & IOO,O & IOO,O & $9 \mathrm{I}, 6$ \\
\hline GAROTOS & 92,9 & 83,3 & 53,3 & 85,7 & 50,0 & IOO,O & 75,0 & $9 \mathrm{I}, 7$ & 92,3 & IOO,O & 82,4 \\
\hline
\end{tabular}

Fonte: Elaboração própria.

A Tabela 6 apresenta a situação socioeconômica dos diversos subsetores de Ribeirão Preto: norte (N-2, $\mathrm{N}-5$, Nio), sul (S-I), leste (L-7), oeste (O-6, O-I2) e central (CE).

TABELA 6

Dados socioeconômicos de subsetores da cidade de Ribeirão Preto

\begin{tabular}{|c|c|c|c|c|c|c|c|}
\hline \multirow{2}{*}{$\begin{array}{l}\text { SUB- } \\
\text { SETOR }\end{array}$} & \multirow{2}{*}{$\begin{array}{l}\text { NoESCOLAS } \\
\text { VISITADAS }\end{array}$} & \multirow{2}{*}{$\begin{array}{l}\text { JOVENS } \\
\text { 15-17 ANOS (\%) }\end{array}$} & \multicolumn{2}{|c|}{ NÃO FREQUENTAM A ESCOLA (\%) } & \multirow{2}{*}{$\begin{array}{l}\text { PESSOAS COM } \\
\text { TRABALHO } \\
\text { REMUNERADO (\%) }\end{array}$} & \multicolumn{2}{|c|}{ SALÁRIO MÉDIO (R\$) } \\
\hline & & & 6-14 ANOS & 15-17 ANOS & & HOMENS & MULHERES \\
\hline $\mathrm{N}-2$ & I & 3,0 & 3,9 & 4,9 & 44,9 & $3 \cdot 389$ & I. 964 \\
\hline $\mathrm{N}-5$ & I & 4,9 & 2,2 & $\mathrm{I} 6,6$ & 53,9 & I.052 & 675 \\
\hline N-IO & I & 3,5 & $\mathrm{I}, 2$ & 3,4 & 47,2 & 2.105 & I.IOI \\
\hline S-I & I & 3,2 & 3,6 & I8, 2 & 54,3 & 2.I9I & 899 \\
\hline L-7 & I & I, 9 & 0,9 & I6, 7 & 45,0 & I. 203 & $8 \mathrm{I} 3$ \\
\hline O-6 & 2 & IO, O & 3,6 & $\mathrm{I} 5,2$ & 50,4 & 772 & 490 \\
\hline $\mathrm{O}-\mathrm{I} 2$ & I & $5, \mathrm{I}$ & 7,6 & 32,7 & 48,7 & 493 & 315 \\
\hline CE & 2 & 6,4 & 3,2 & II, 3 & 52,0 & 697 & $42 \mathrm{I}$ \\
\hline \multicolumn{2}{|c|}{ Ribeirão Preto } & 28.563 & 4,5 & $\mathrm{I} 6,2$ & 50,4 & I. 262 & 700 \\
\hline
\end{tabular}

Fonte: Censo Demográfico, 2000

É preciso apontar que a soma das escolas visitadas não contabiliza I2, pois duas delas (uma na região sul e outra na região leste) não aderiram ao projeto. 